Article

\title{
What Is Body, What Is Space? Performance and the Cinematic Body in a Non-Anthropocentric Cinema
}

\author{
Anne Rutherford \\ Cinema Studies, School of Humanities and Communication Arts, Western Sydney University, \\ Bankstown Campus, Bldg 5, Locked Bag 1797, Penrith, NSW 2751, Australia; \\ a.rutherford@westernsydney.edu.au \\ Academic Editor: Annetta Alexandridis \\ Received: 6 December 2016; Accepted: 23 October 2017; Published: 9 November 2017
}

\begin{abstract}
The assumption of a clear demarcation and hierarchy between figure and ground has long informed key approaches in film studies to bodies and space. However, many filmmakers working in both animation and live cinema have confounded this hierarchy, working with an integration of figure and ground on equal terms to explore the full performative potential of the cinematic body. In the animation work of Einar Baldvin, this strategy is an Expressionist one, blurring the boundaries between figure and ground in order to project affective and psychic states onto the space around the body. In Wong Kar-wai's The Grandmaster, this blurring of boundaries between figure and ground eschews an Expressionist mode, working instead to render, in aesthetic form, a biophilosophy that emphasizes the continuity between bodies and environment to explore the possibilities of non-anthropocentric cinematic modes. An experimental writing style here serves to trace the energetic unfolding of these strategies across both films in order to frame the question, 'what is body here, what is space', and to ask how we as viewers engage with this embodied mode.
\end{abstract}

Keywords: film studies; cinematic body; cinematic space; animation; Hong Kong cinema; mise en scène

\section{The Pride of Strathmoor (Baldvin 2014)}

Imagine a world cleaved in two by the color of a man's skin. Where color seeps from the skin like vapor in thick black globs. Draw this world of dense black coal and bright white light in solid mass of ink and splitting shards that smear across the white is might is right of the faltering mind of a churchman wedded to the Confederate flag. Spray this world with coffee, rusty splotches that jig and jive across the screen to the upbeat tune of Dixie, sepia stains that leak across the madman's mind.

This is the world of Pastor John Deitman, Georgia, 1927, as told in his journals.

Where a look askance could be met by a noose in the night in the sycamore tree. Where crosses spark and flare across the night sky and white hoods bob and weave in the hellish glow.

Except, except ... in the boxing ring the white pride of Strathmoor will fight the black man's choice.

'Henry is my own, my knight. The rope is strong but his body his fists are the instrument of God's will.'

Say it to yourself. Spit it out in a raspy whisper. Scrape the voice across the lump that rises in the throat with the demon madness. Lunge into the shattering mind as it lurches over the abyss into hatred-driven mania. Dive into an ear as a bat yanks its scrawny limbs from the orifice, all Gothic angles, and flies away.

'I know what you are I know what you are I know what you are.'

Heads turn into crows and a crow tears strips from its own talons.

'The crows the crows the crows'. (All quotations from Baldvin 2014) 
A black sun burns and everywhere bodies melt into ink and miasmas spread across the frame until all is black (Figures 1-3).

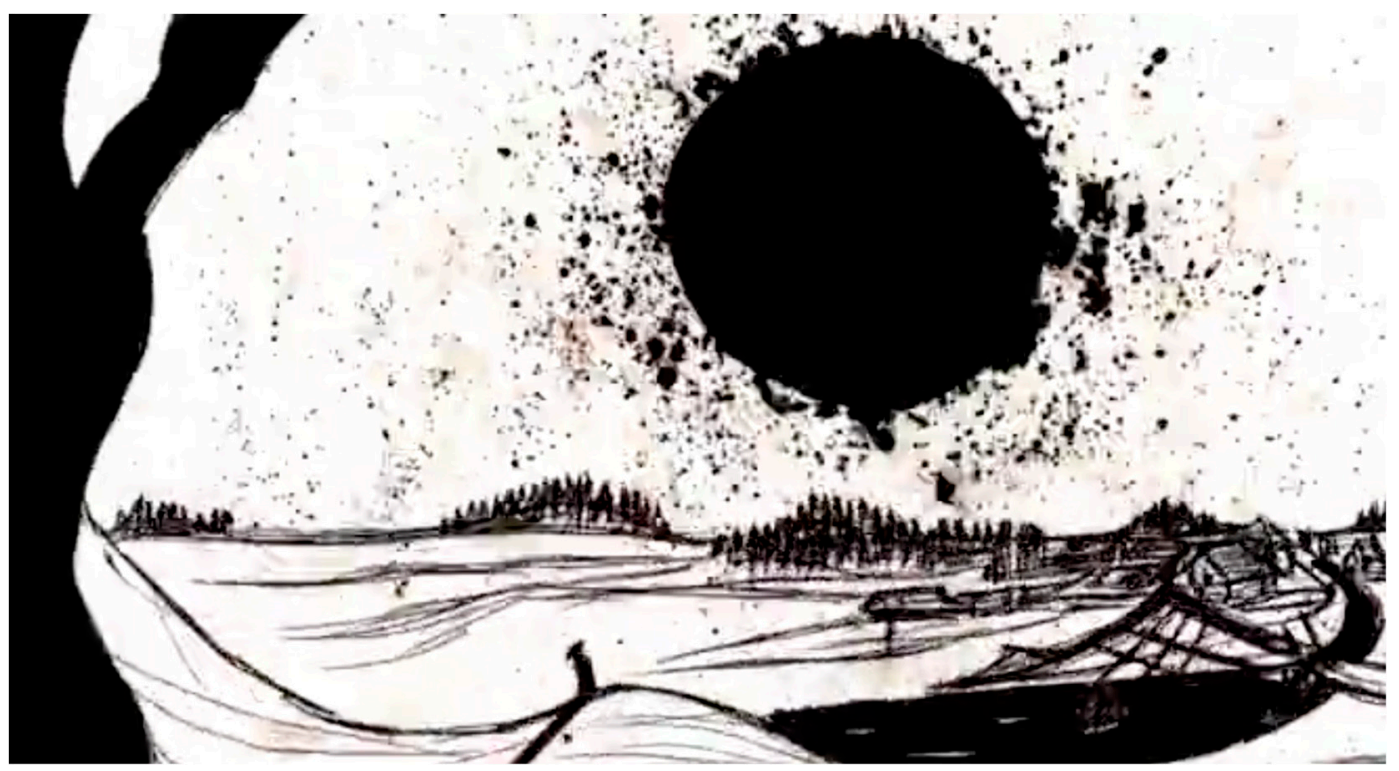

Figure 1. A black sun burns. Frame capture, The Pride of Strathmoor (Baldvin 2014).

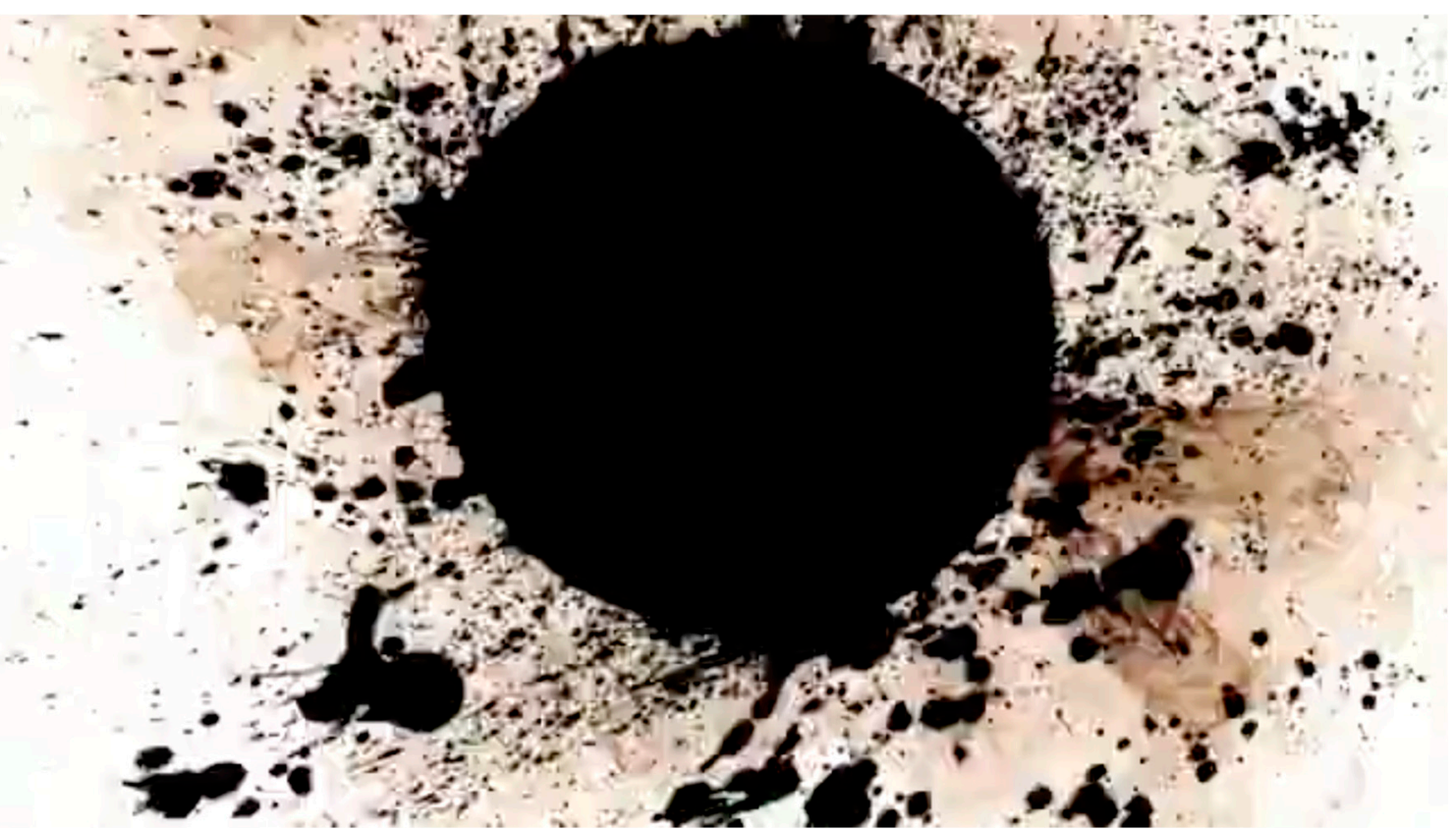

Figure 2. The black sun burns until all is black. Frame capture, The Pride of Strathmoor (Baldvin 2014). 


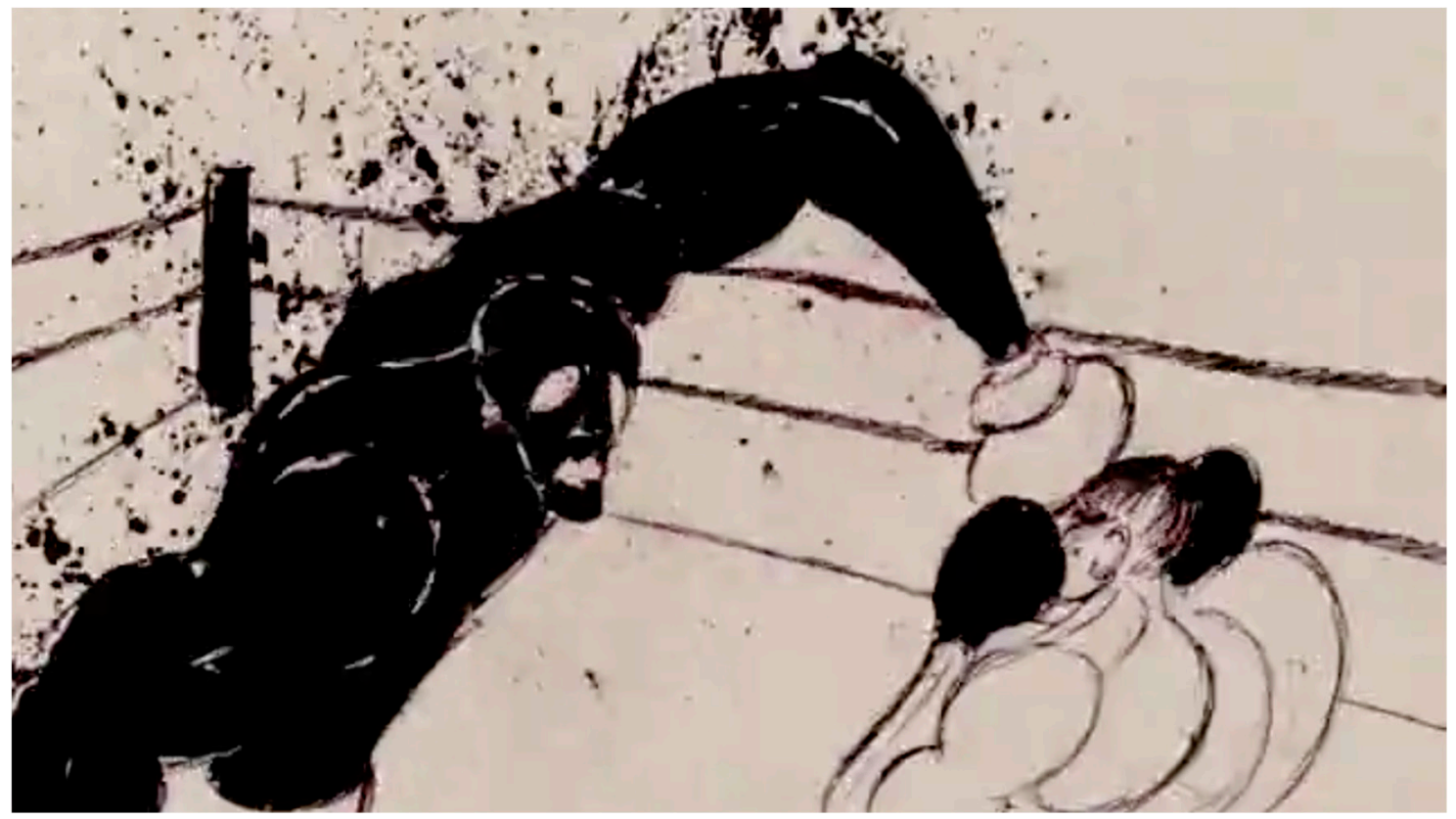

Figure 3. Bodies melt into ink. Frame capture, The Pride of Strathmoor (Baldvin 2014).

It is a perilous path that plunges straight into the heart of madness but this is the path that California-based filmmaker Einar Baldvin chooses. Like his German Expressionist antecedents, he sucks the world in with him. If you're going through hell, they say, don't stop, but there is no light at the end of this tunnel, just a world whose logic starts to jag and shudder, its contours rent asunder (Figure 4).

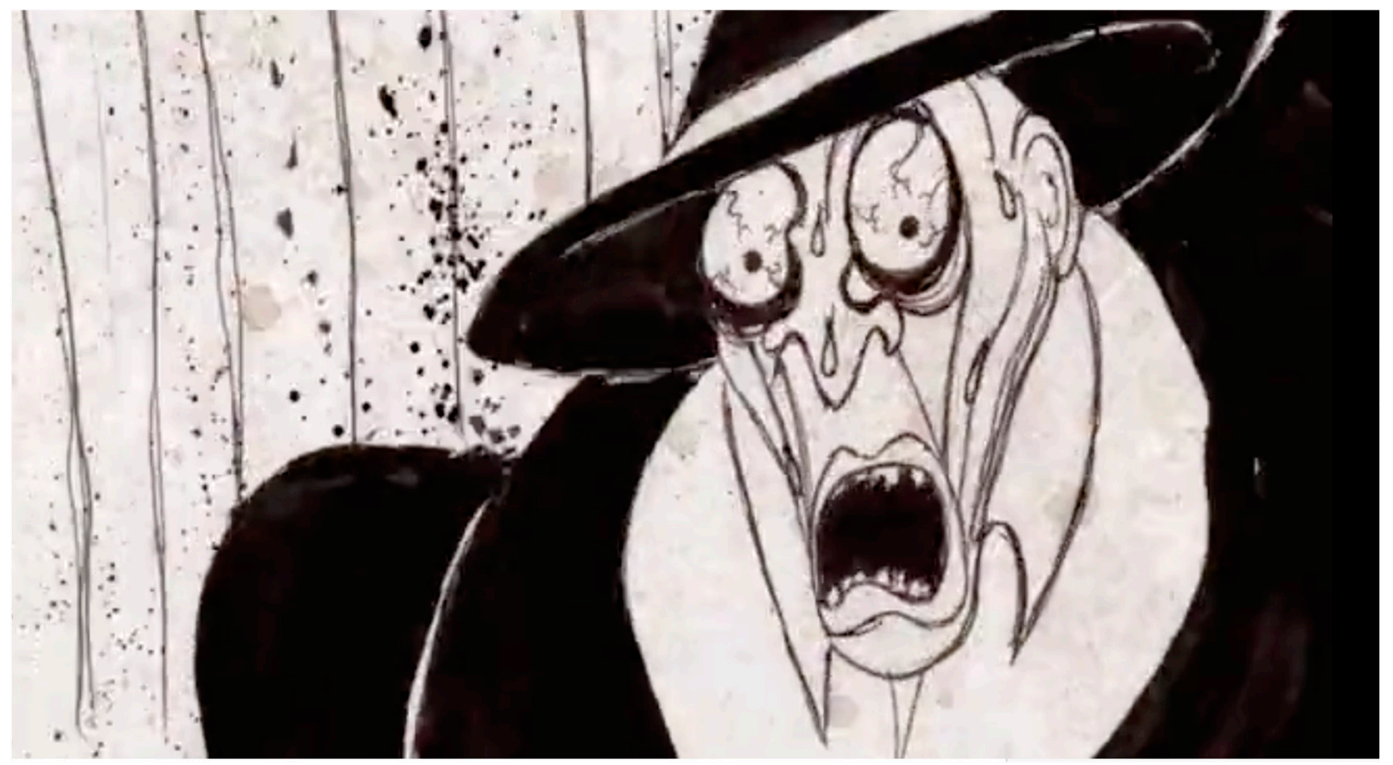

Figure 4. A world whose logic starts to jag and shudder. Frame capture, The Pride of Strathmoor (Baldvin 2014).

This nightmare of a mind in free-fall is an animator's dream. Baldvin's pen dances in tandem with the flux and flow of this splintering mind, translating its aberration into line and blob. Every animator knows the passion for a world that buckles to the will of its creator but rarely is the animator's art so perfectly matched to its task. Baldvin is a master of what the great Soviet filmmaker, Eisenstein, called the 'plasmatic' - the endless capacity of form to morph and mutate in the hands of the animator 
(Leyda and Kleinman 1988). Bringing inert matter to life is the core of animation and Baldvin's trump card is the way he applies this principle to both figure and ground. Not only does the wing of a crow in flight amplify and curl upward in a sinister snarl; the sky the crow flies through also breaks out into a pox across the skin of the screen and the borders of bodies melt into the disease that spreads across the disintegrating frame (Figure 5). The stark division of black ink and white frame is a perfect analogue for this bipolar universe and the blotches that break out across the image a cryptic cipher for its unravelling.

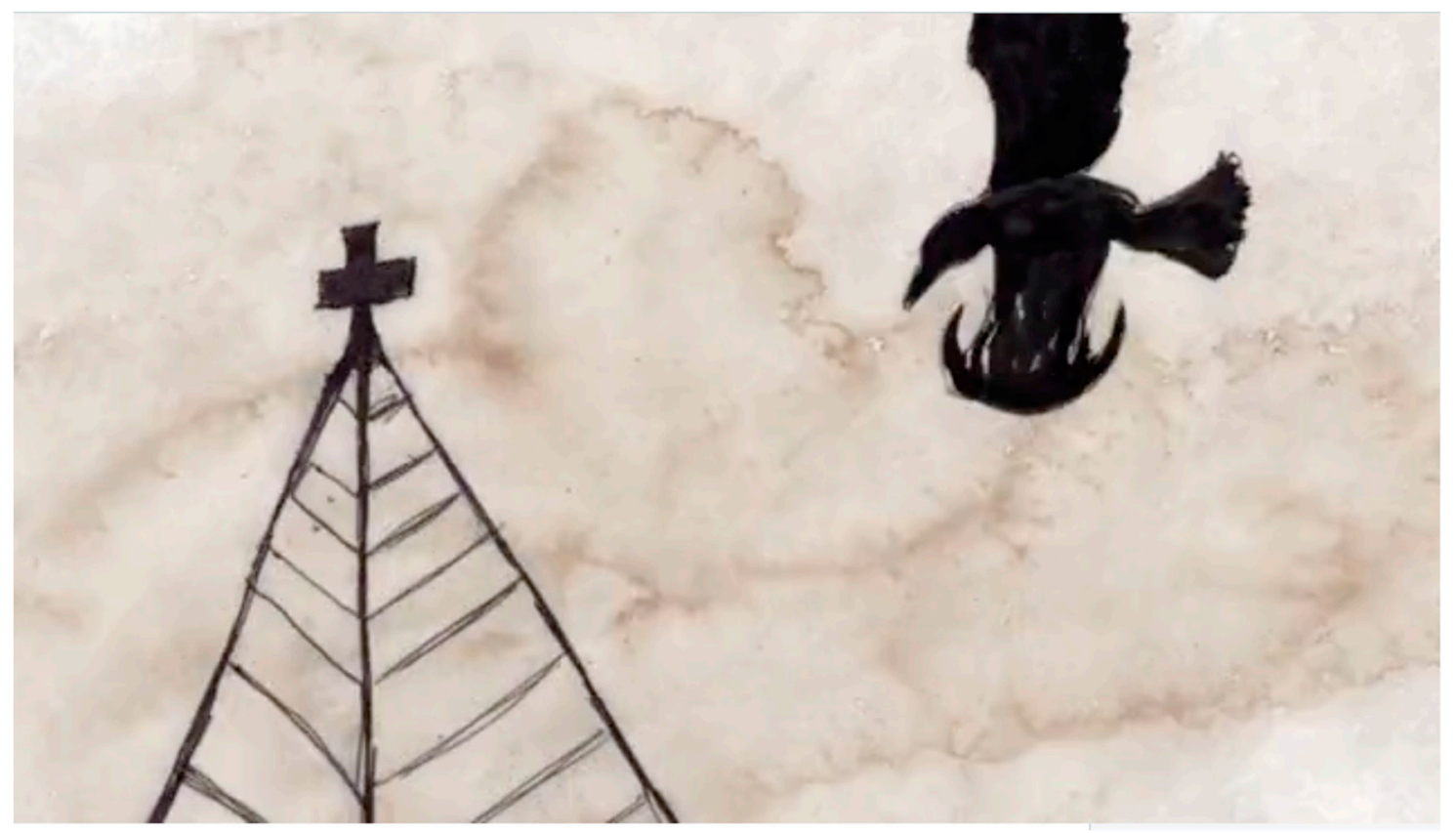

Figure 5. The sky that the crow flies through breaks out into a pox. Frame capture, The Pride of Strathmoor (Baldvin 2014).

What is figure here, what is ground? What is body, what is space? Baldvin has dissected the pathology of racism as, literally, fear of a body contaminating the space around it. As an animator, he renders this phobic vision concrete, translating this literal understanding into an animation strategy that impregnates both figure and ground equally with paranoia, both figure and ground brought to life as sites of transformation and intensity. In The Pride of Strathmoor (Baldvin 2014), when the flap of the wing of a bird in flight reverberates across the space of a frame, we go with it. We too are dispersed across the frame. As viewers, we don't need to read this literally, to translate it into concepts: 'the pastor imagines a demonic force spreading across the world.' We get it. We are drawn into a mode of viewing in which we cease translating images and sounds into literal concepts and experience them in all their amorphous embodied multiplicity, drawn into a relationship with all the elements of the shot in complex, "polyvocal" ensembles.

From his native Iceland, Baldvin brings an outsider's eye to this foray into the furnace of the deep South, but an insider's experience to his rendering of the boxing ring. For three years he trained, honing his knowledge of the craft in his own body. The rush of sweat and testosterone, the smash of plummeting fists and the light-footed dance of the pugilist flesh out this conflict. Baldvin has closely studied Scorsese's techniques for constructing a fight from inside the senses of the boxer, in the whoosy slip and slide into slow motion and back and the acoustic distortion that reverberates from inside a ruptured eardrum (Scorsese 1980). Raging Bull (Scorsese 1980) jostles in this film with Dr Caligari (Wiene 1920), and The Night of The Hunter (Laughton 1955) lurks menacingly in the shadows.

The Pride of Strathmoor took international animation festivals by storm, scooping numerous awards. Baldvin's graduation film from University of Southern California is a torchbearer for the 
achievements of 2-D drawn animation. Eschewing the drive to hyper-realism that dominates much computer-generated work, the film is like a manifesto that throws down a gauntlet to those who have yielded to the lure of 3-D animation. Match this! Who cares for verisimilitude! Forget that solid form! This is the real art of animation! See how your box of tricks squares up to this master work!

\section{Writing the Embodied Moment}

To get inside a film, to find a way to write from inside the way each moment unfolds: this attempt to "think with a film" rather than just "think about a film" is the holy grail for a certain strand in film criticism. Described by some as a marginalized 'maverick' criticism, this writing aims to produce a quality of presence in the writing itself that draws readers into the experience of watching the film. For some film scholars interested in the dynamics of embodied spectatorship, the rhetorical strategies of this maverick criticism provide a model for a kind of performative writing that challenges the distanced commentary common to much of film theory and bridges the assumed divide between film theory and film criticism. Rather than distance and detachment, proximity is its ethos. To come close to the moment through the writing, to evoke, through language, the 'flash of embodied meaning' that Laura Marks discusses: this is the aspiration of a kind of film writing that seeks a 'language that draws close enough to its object to make the sign ignite', as Marks (1999, p. 141) writes. The aim is to bring alive in the written word the intense, embodied sensory-affective encounter with cinema. ${ }^{1}$

The question of ekphrasis-'a description in words of a plastic art' - has been much less fully explored in film studies than in discussions in art history and literary theory about the status of commentary and its relationship to the object (Stern and Kouvaros 1999, p. 10). ${ }^{2}$ In an influential précis of the concept and its significance for film studies, Lesley Stern and George Kouvaros propose the need to understand critical writing itself as performative. They pose the challenge of finding a writing practice that can address performance, embodiment and affect, in a way that is adequate to the task of conveying the 'sense of corporeal presence' of a performance, and can '[convey] a sense of performative affect' (Stern and Kouvaros 1999, pp. 11-12).

Whereas the maverick critical tradition provides models of a performative writing that can capture and evoke these moments of embodied, affective presence, the challenge of film theorists committed to understanding the centrality of embodied affect in film spectatorship is to find a way to integrate these rhetorical strategies with a more theoretical endeavor: to embed the theoretical insights within the performative writing. This current article adopts an experimental approach to push the limits of how far this theoretical-performative integration can work. The Pride of Strathmoor (Baldvin 2014) provides a productive site for exploring this writing/conceptual practice in the context of 2-d drawn animation, to explore how animation can build the maximum tactile density to draw the viewer in close, into the embodied "thickness" of the moment. Wong Kar-wai's The Grandmaster, a live-action analogue film, further challenges the scholar/writer to integrate a performative understanding of mise en scène into the strategies of the writing in order to understand-and evoke-how the film reconfigures the relationships between bodies and spaces and to investigate the cultural ramifications of this reconfiguration.

\section{The Grandmaster (Wong 2013)}

'Kung fu-two words.

Horizontal. Vertical.

Make a mistake-horizontal. Stay standing and you win.' (Wong 2013)

\footnotetext{
1 For an extended discussion of this idea, see Rutherford 2011, p. $98 \mathrm{ff}$.
}

2 On ekphrasis, see Rutherford 2011, p. 93 ff. 
A thousand projectiles, each one a kinetic prism of light: catching, bouncing, bending. Bullets flying on a thousand different trajectories or joined together in a moving threshing wall. Particles that drift, particles that drive: crashing, splashing, glistening. Fluid chaos plus light. Rain: it's every cinematographer's dream (Figure 6).

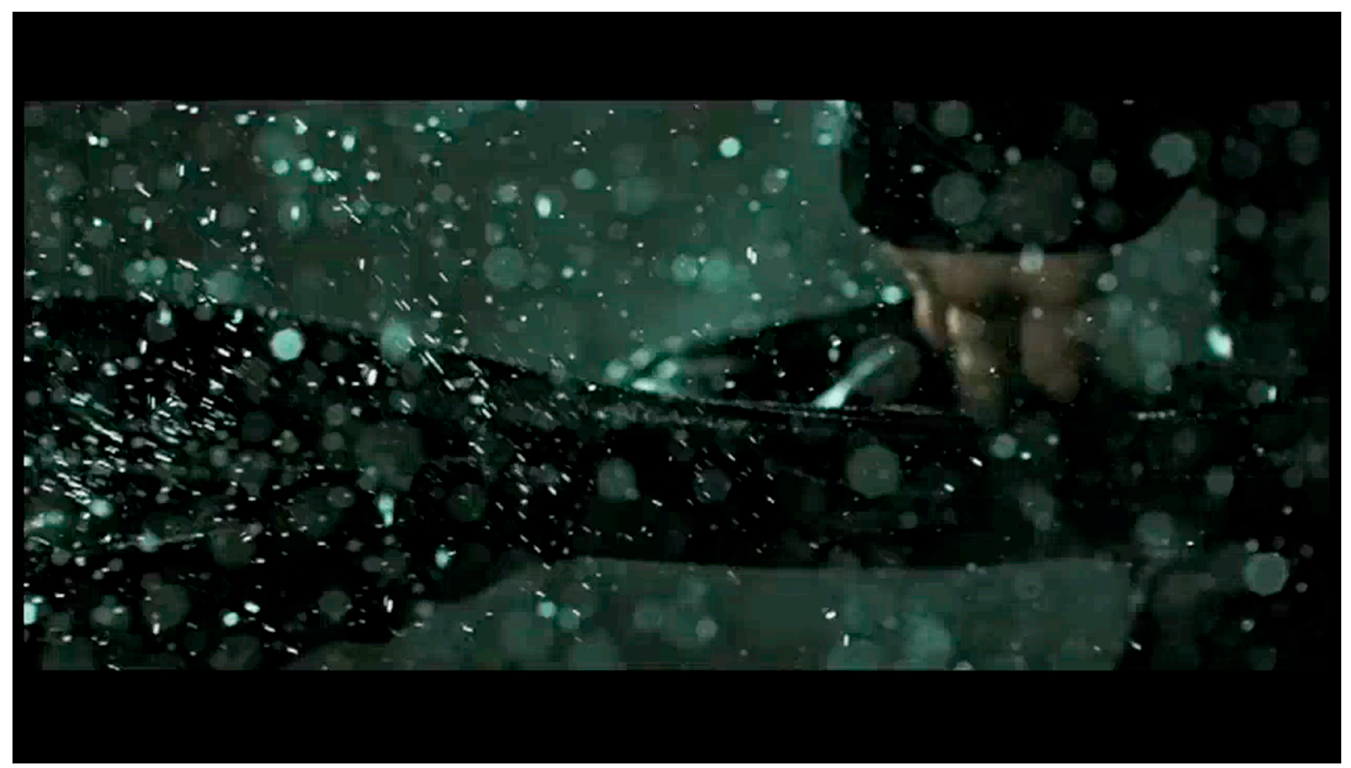

Figure 6. Particles that drift, particles that drive. Frame capture, The Grandmaster (Wong 2013).

The body punches the pavement, streaking, pounding, striking, beating. Another axis, crashing against the upright human bodies and those that skid across the ground. The body of water punches the ground as the human bodies block, throw, lunge-two axes of action in the frame that ricochet off each other. It is unclear whether the driving, splashing rain registers the impact of the fighters' bodies or vice versa. The rain enmeshes the fighters in a web of materiality: air/space become visible, dense (Figures 7-10).

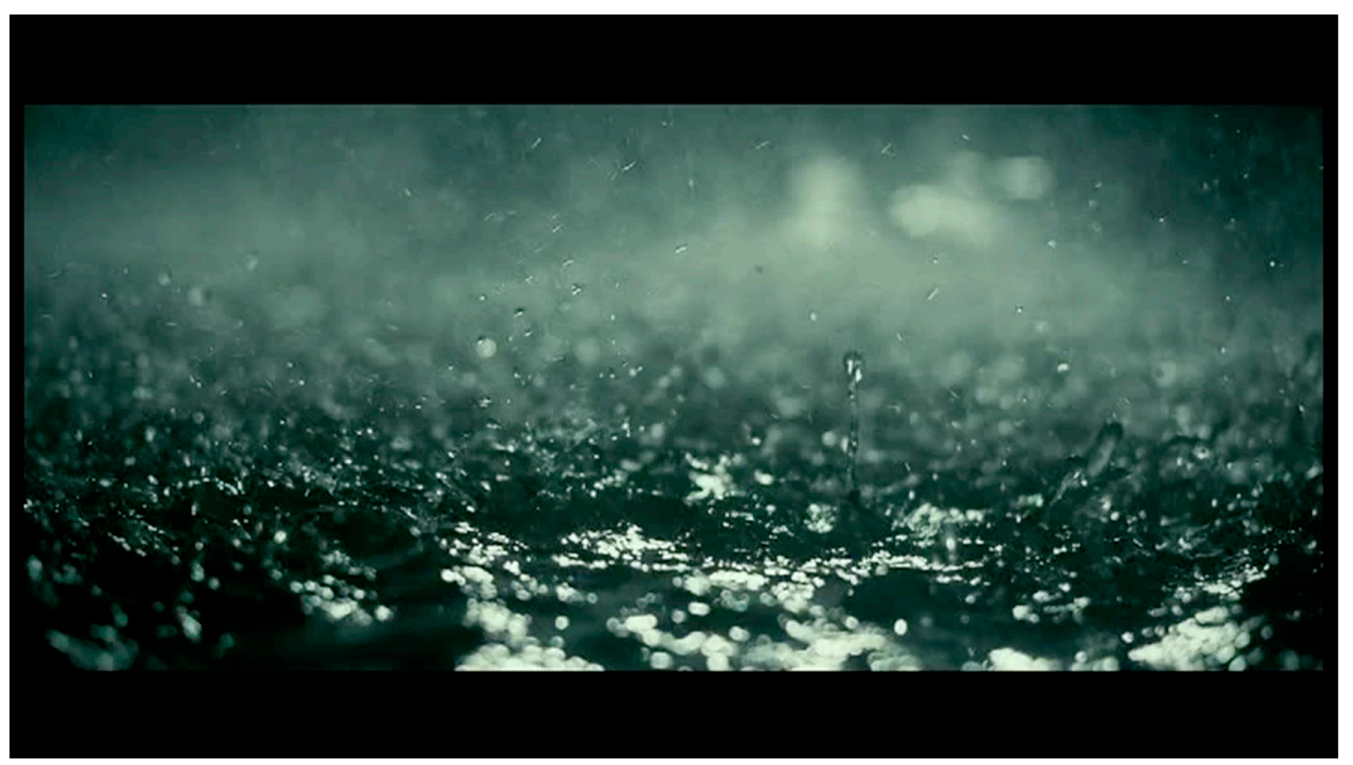

Figure 7. Rain punches the pavement, streaking, pounding, striking, beating. Frame capture, The Grandmaster (Wong 2013). 


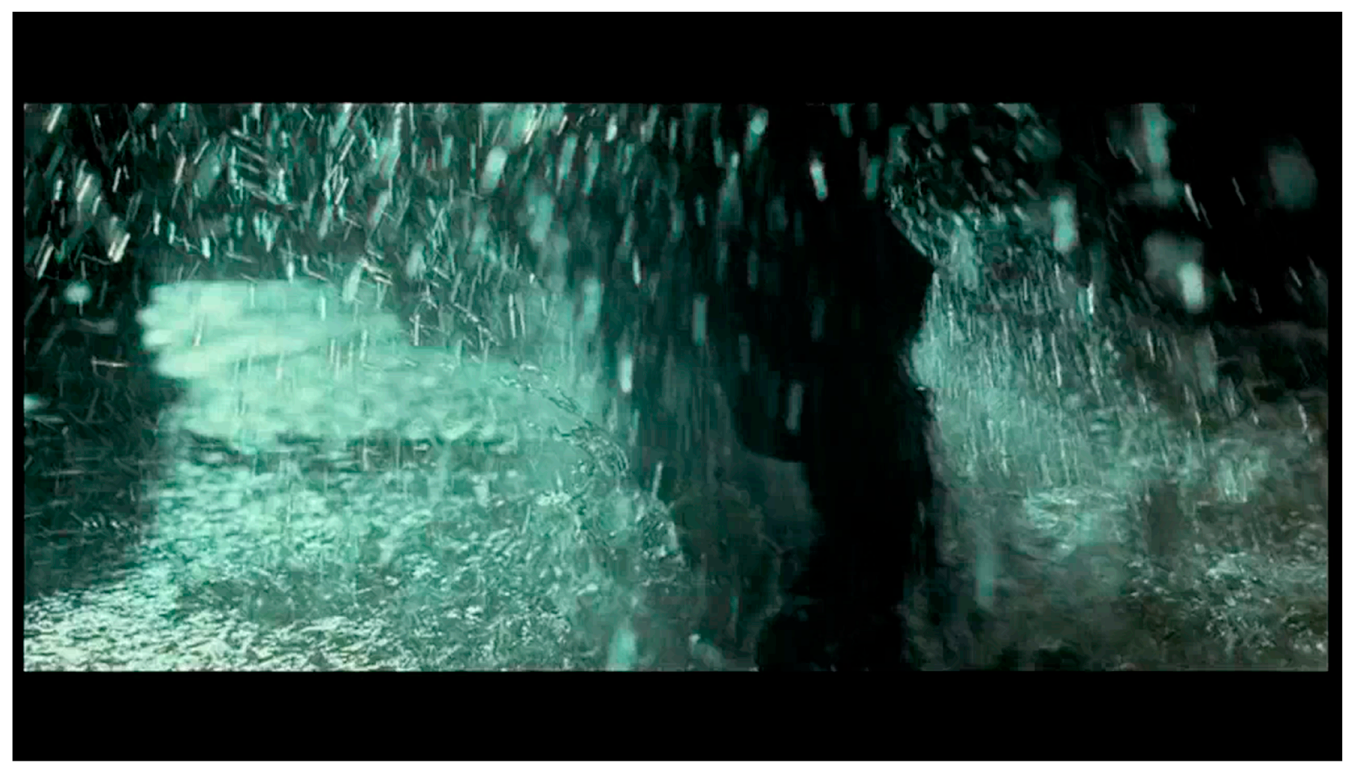

Figure 8. Water punches the ground as the human bodies block, throw, lunge. Frame capture, The Grandmaster (Wong 2013).

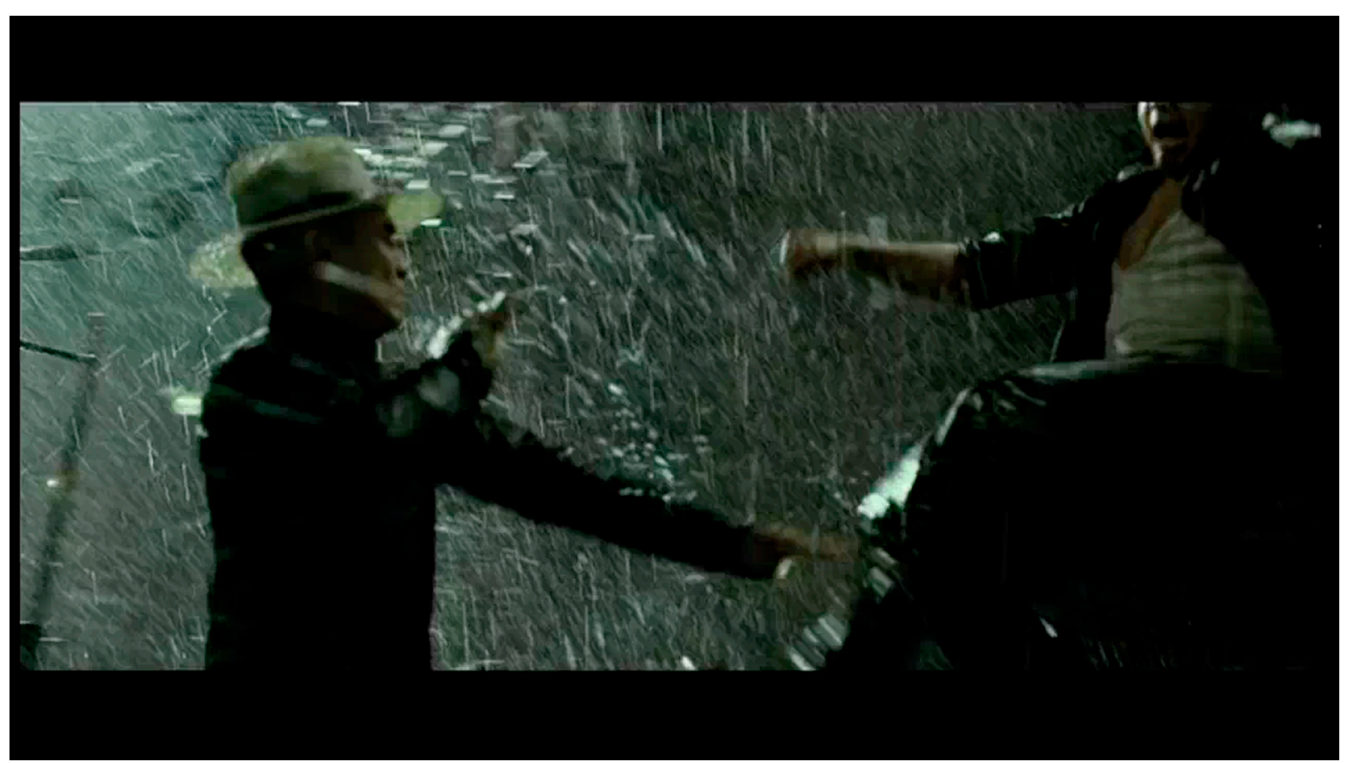

Figure 9. Two axes of action in the frame that ricochet off each other. Frame capture, The Grandmaster (Wong 2013). 


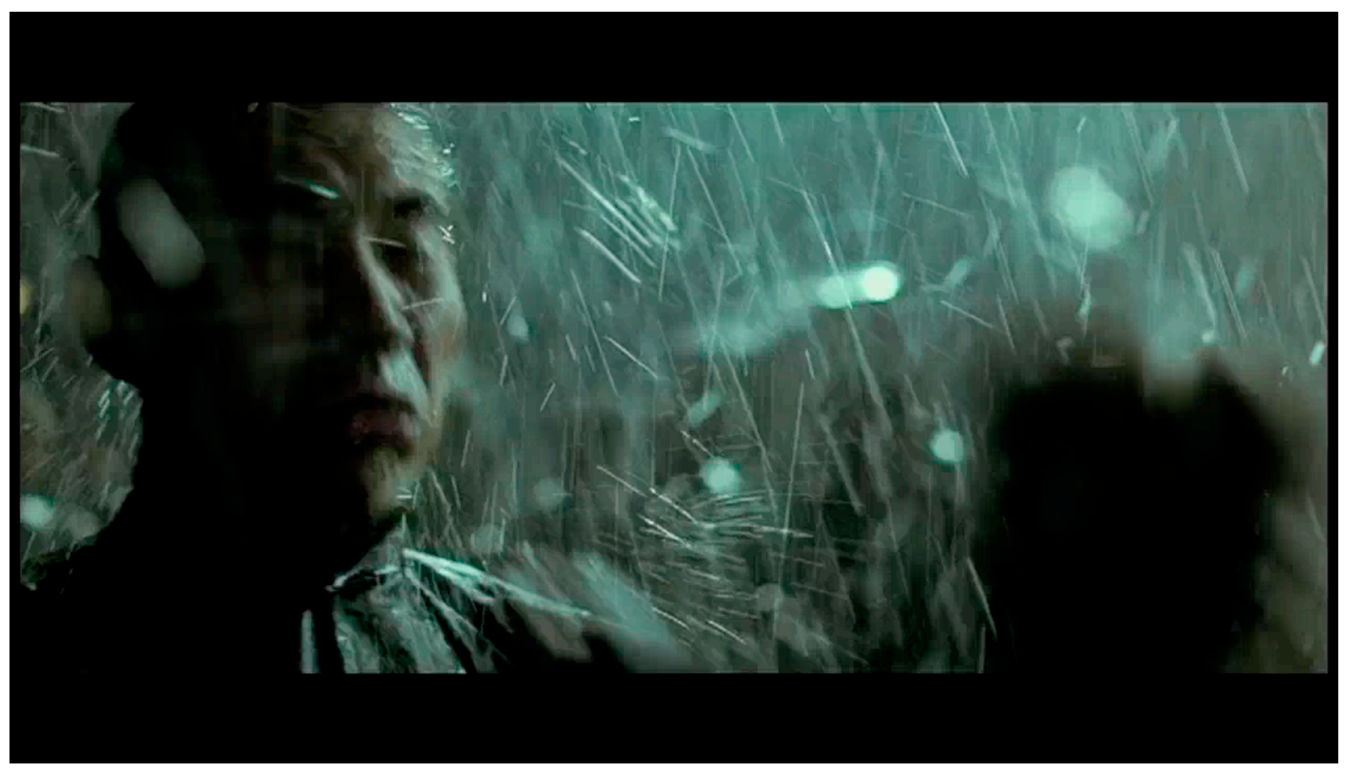

Figure 10. A web of materiality: air/space become visible, dense. Frame capture, The Grandmaster (Wong 2013).

In the opening fight scene of The Grandmaster (Wong 2013), director Wong Kar-wai and cinematographer Philippe Le Sourd choreograph the action of the rain as much as choreographer Yuen Woo-ping is choreographing the action of the fighters, confounding the figure-ground distinction. The bodies of the fighters bring the body of the rain to life, make it perform. Human body and environment are one and movement is integral to both. Kung fu, rain style.

Wong says that the Wing Chun kung fu style 'is not actually very eye-pleasing; it's too straightforward, too simple. The only thing you can emphasize is its directness, and also its power' (Ebiri 2013). The solution was to stage the fight in heavy rain and capture that rain in 'step print and languorous high-frame slow-motion' (Rizov 2014). He says, 'when you shoot it at, like 500 frames per second, you can actually see how these raindrops interact with the actions, it's very beautiful' (Stasukevich 2014). ${ }^{3}$ The result is raindrops elongated into a moving thatch of white streaks, pools shimmering with an uncanny movement and crystalline splashes that capture the precise trajectory of water across the frame (Figures 11 and 12).

The Grandmaster (Wong 2013) builds on a long tradition of animating the "air" in East Asian cinema, which in turn draws on calligraphic traditions. Film scholar Wong Kin-yuen writes that, 'in Chinese theories of calligraphy, papers have different textures and ways of absorbing ink, hence their different expressive characteristics' (Wong 2005, p. 272). The relationship between the ink and the texture of the paper makes the whole. What the western tradition sees as empty space is just as full as the point where the mark of the pen hits the page. Wong Kin-yuen traces the influence of this tradition in a 'biophilosophy' informing the ways Chinese martial arts '[create] nuances of forceful intersection between materials and matters' (Wong 2005, p. 273). In his account, this biophilosophy, with its heritage in Daoist concepts of shi or qi, emphasizes the 'milieu of interrelationships between living things and their environments' (Wong 2005, p. 277). Rather than seeing "air" as simply empty space, the Daoist tradition sees qi (energy/vitality). ${ }^{4}$

3 In an interview with American Cinematographer, Le Sourd says that he was actually filming at 1000 frames per second (Sejean 2013).

4 According to Daniel Reid's explanation of the concept of qi, 'Chi means "breath" and "air", and by extension it also denotes "energy" and "vitality" [ ... ] Chi manifests itself in myriad ways throughout the realms of nature, the cosmos, and the human system. [... ] Chi is the fundamental stuff of the entire manifest universe, the basic building block of all matter, 


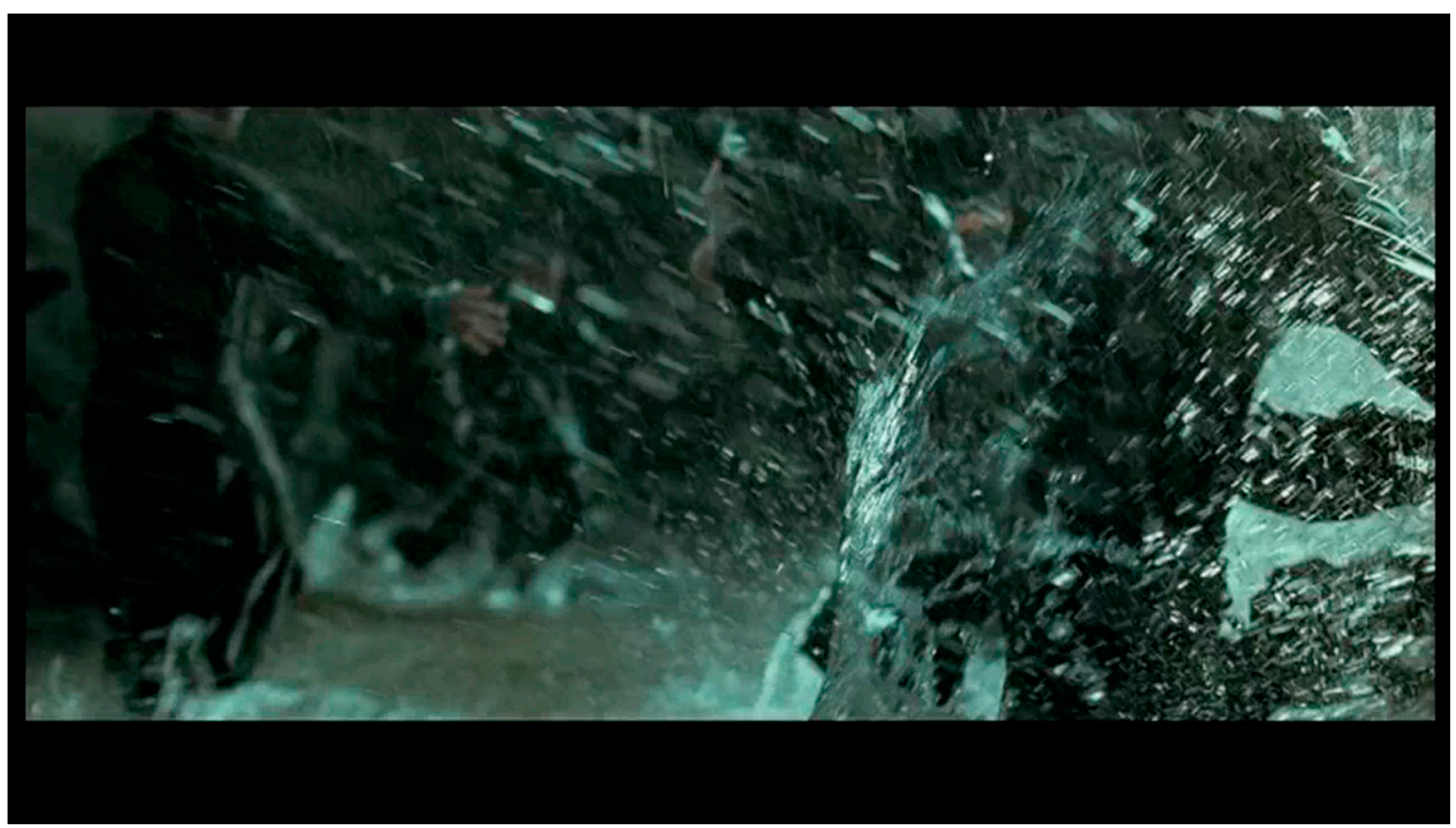

Figure 11. Raindrops interact with the actions. Frame capture, The Grandmaster (Wong 2013).

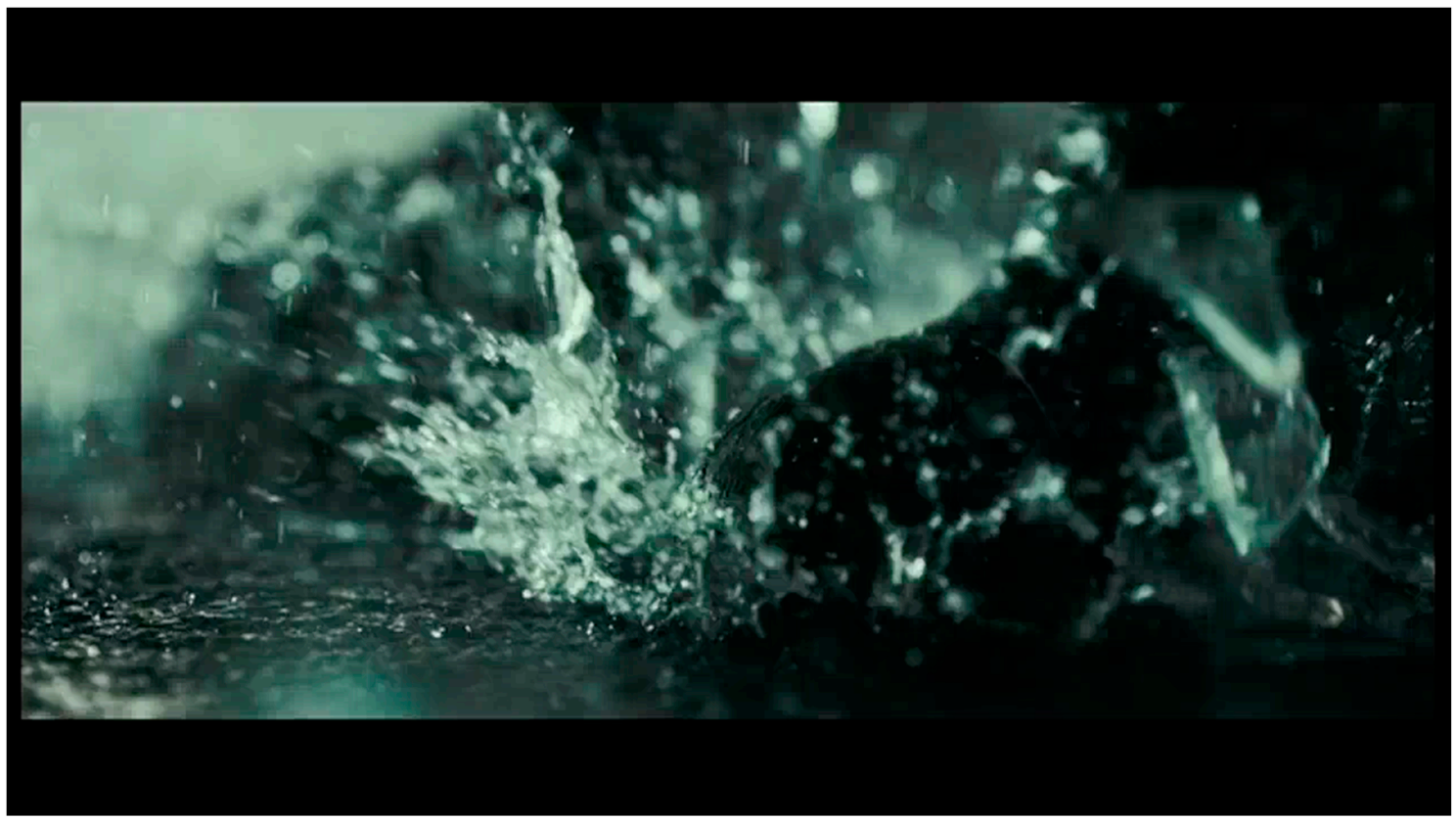

Figure 12. Crystalline splashes that capture the precise trajectory of water. Frame capture, The Grandmaster (Wong 2013).

Wong Kin-yuen describes wuda pian-a term he uses to cover wuxia (martial hero films), kung fu films and martial arts films - as a privileged contemporary site for exploring the 'means [by] which body projects its transformational capacities into the world' and 'body/movement images

the immaterial energy that constitutes all material form. [ ... ] Chi is therefore the basic energy that comprises all matter and animates all living things, and the fundamental functional force that drives all activities and transformations in nature and the universe. [ ... ] Chi is the basic life force all three levels of human existence-body, energy and mind. [ ... ] Chi also constitutes the dynamic polar field in which all energy moves and from which all power springs' (Reid 1998). 
interact with their environment in terms of mutual performance' (Wong 2005, p. 281) (Figure 13). He cites Eisenstein's recognition that the machine of cinema [can ... ] invent new and finer articulations of the linkages between human and the world' (Wong 2005, p. 284). He describes Hong Kong martial arts cinema as 'a kind of painting on film in the fluidity of multiplane animated perspectives' (Wong 2005, p. 269).

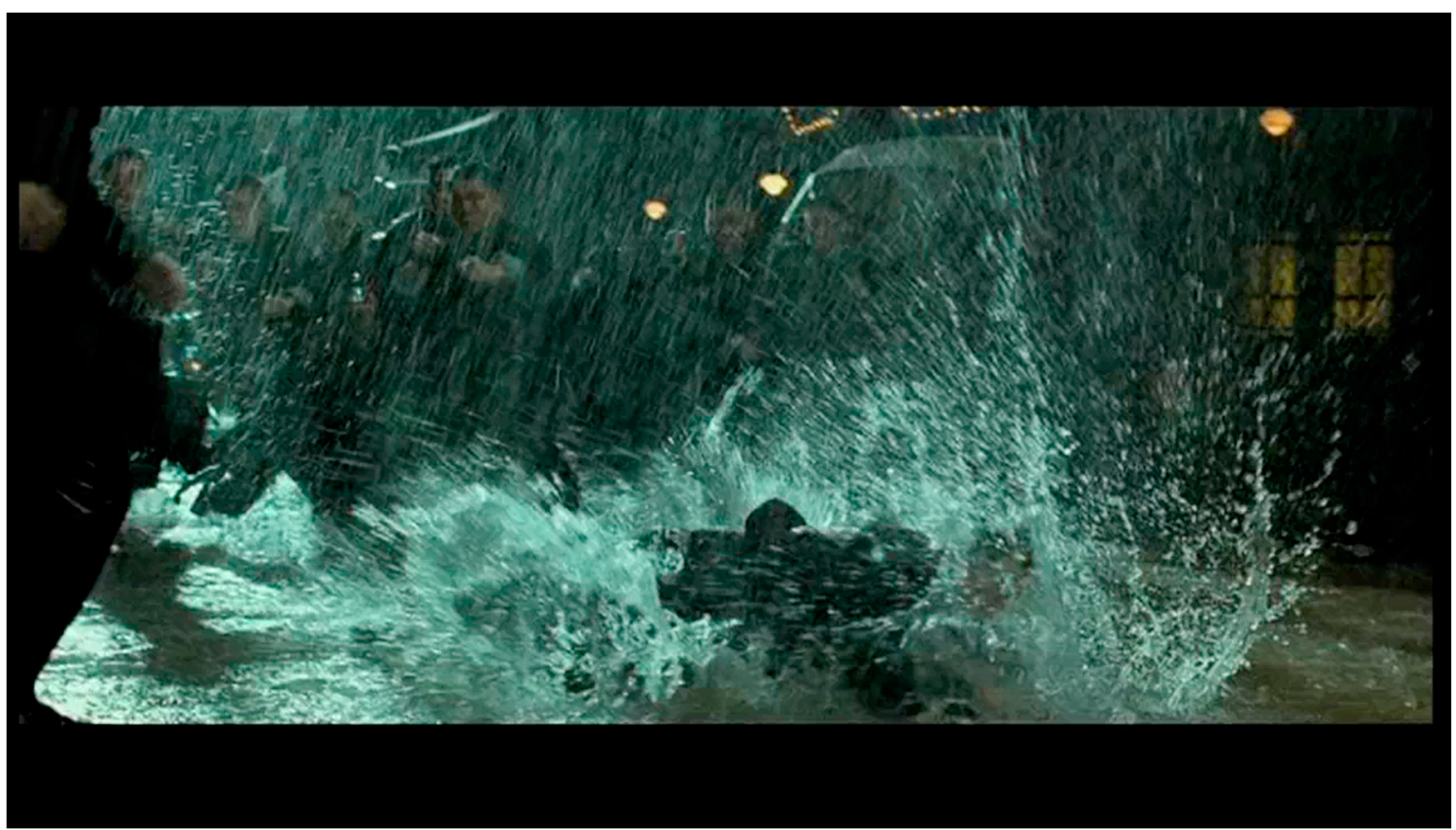

Figure 13. Body/movement images interact with their environment in terms of mutual performance. Frame capture, The Grandmaster (Wong 2013).

In Hong Kong wuda pian, Wong Kin-yuen finds a perfect synthesis of 'an ancient technology of embodying the force vitale [in ... ] bodily movement and its aesthetic, expressive dynamics of energy flow [ ... ] with a modern technology for narrating that movement' (Wong 2005, pp. 284, 269). In the film that Wong cites as his example of this synthesis, Ang Lee's (2000) Crouching Tiger, Hidden Dragon, he sees an exemplary instance of 'a new aesthetics of body in motion choreography seamlessly merged with the virtual interface of a digitalized technological apparatus' (Wong 2005, p. 276). Crouching Tiger, he writes, exemplifies 'what digital composite can do visually to realise such a concept in the Chinese aesthetics of bodily movement' (Wong 2005, p. 277). In Lee's film, wire work, green screen and digital composites are used to seamlessly blend moving figures and ground in ways that extend and intensify the capacities of the human body and maximize both fantasy projection of bodily techne and poetic impact of the new figure-ground composite.

The Grandmaster (Wong 2013) takes this synthesis further in its capacity to animate figure and ground in ways that "give body" to the concept of qi: physically, materially, concretely. The fight scene in the rain effectively animates the 'force vitale' that swirls around and through a body and between bodies and spaces. Qi becomes a haptic register of dynamic energy flow given material form, rendered visible through the confluence of water, light and movement. Wong Kar-wai achieves, in live action and using analogue techniques on $35 \mathrm{~mm}$ film, the multiplane animation that Lev Manovich attributes to the digital. (Wong 2005, p. 275).

The fight in the rain in The Grandmaster (Wong 2013) plays out at such speed that it is difficult to grasp what we are actually seeing. Freezing the moving image into frame captures is the only way to decipher the complexity of this multiplane layering. It is necessary to still the movement to understand how over-cranking the camera enables the animation of kinetic energy to visually realize this concept of the 'force vitale' that flows both within and without the bodies of the fighters. The still 
frames reveal a seamless integration of figure and ground: two bodies, one impulse. Fighters lose their solidity (Figure 14), are obscured behind torrents of driving water (Figure 15). The movement of a fighter translates into water movement as streams spiral off the edge of a twirling hat (Figure 16). Plummeting streaks of water collide with a punch as lines of force ricochet across the frame in a kaleidoscopic spray of light and energy (Figure 17). Fight action converts into water action as the force of a kick flows through into the force of water displaced. This bi-directional impact defies anthropomorphic concepts of the primacy of the human body and their aesthetic materialization in assumed hierarchies between "figure" and "ground". What moves across both is power/energy/qi. (Figure 18) Wong Kar-wai achieves the cinematic body par excellence, as water, light, location, arms, legs, fists, torsos, framing and cutting mesh in a seething tangle of movement so dense at times that it mimics an Abstract Expressionist painting ramped up to a full speed kinetic conflagration (Figure 19).

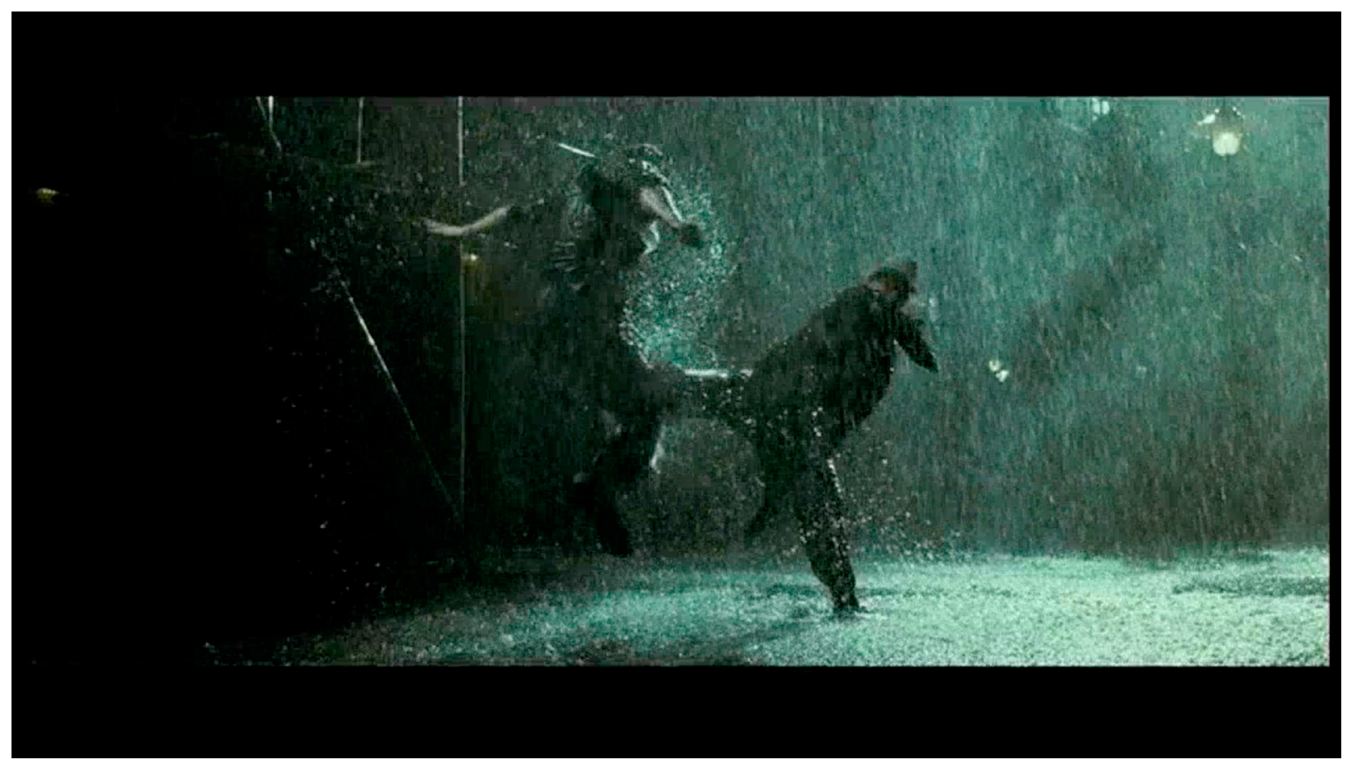

Figure 14. Fighters lose their solidity. Frame capture, The Grandmaster (Wong 2013).

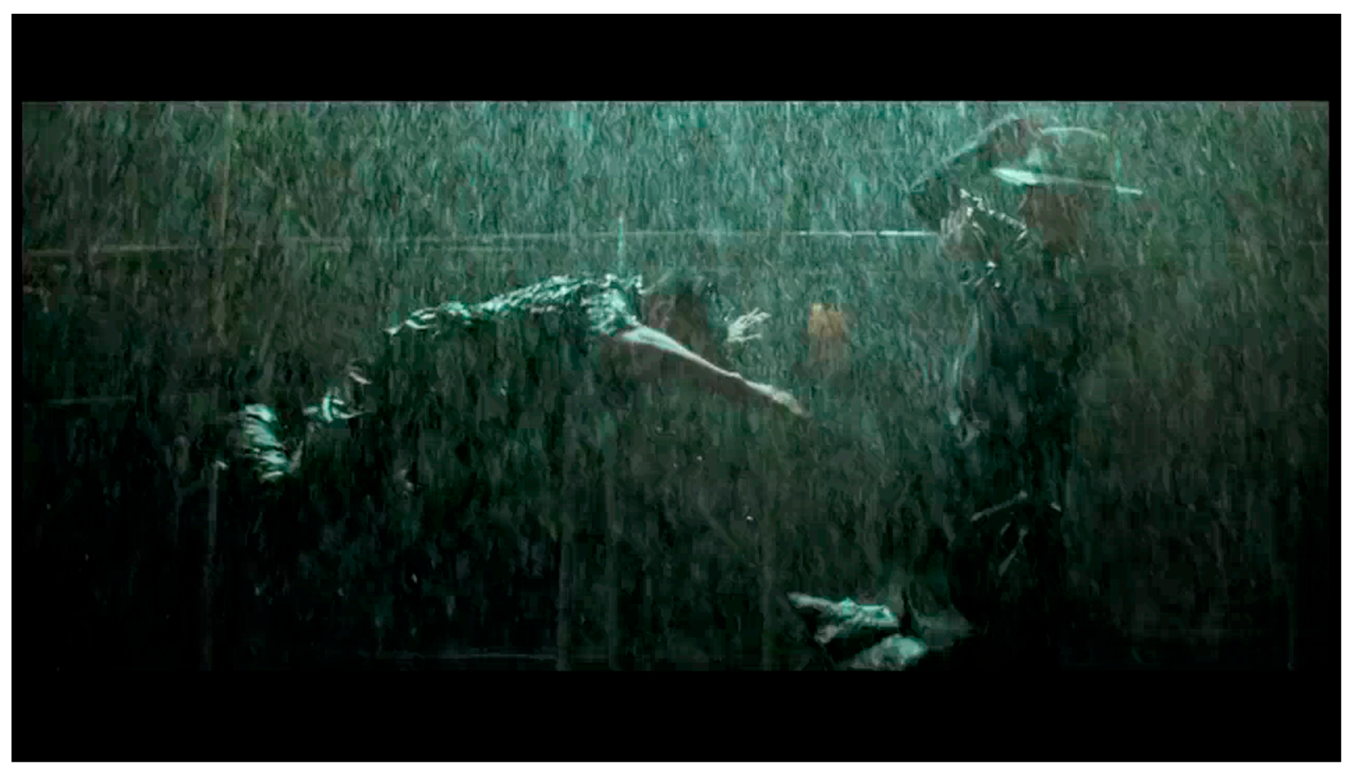

Figure 15. Obscured behind torrents of driving water. Frame capture, The Grandmaster (Wong 2013). 


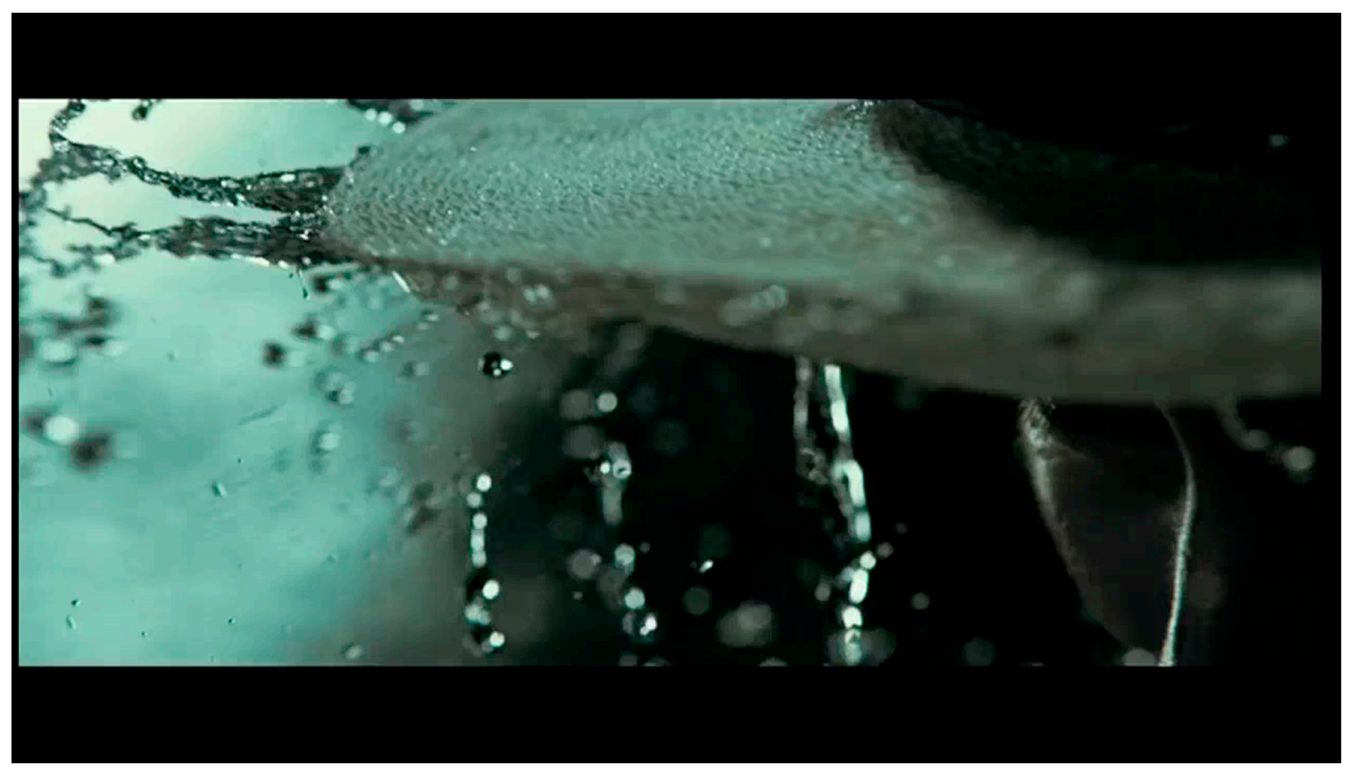

Figure 16. The movement of a fighter translates into water movement. Frame capture, The Grandmaster (Wong 2013).

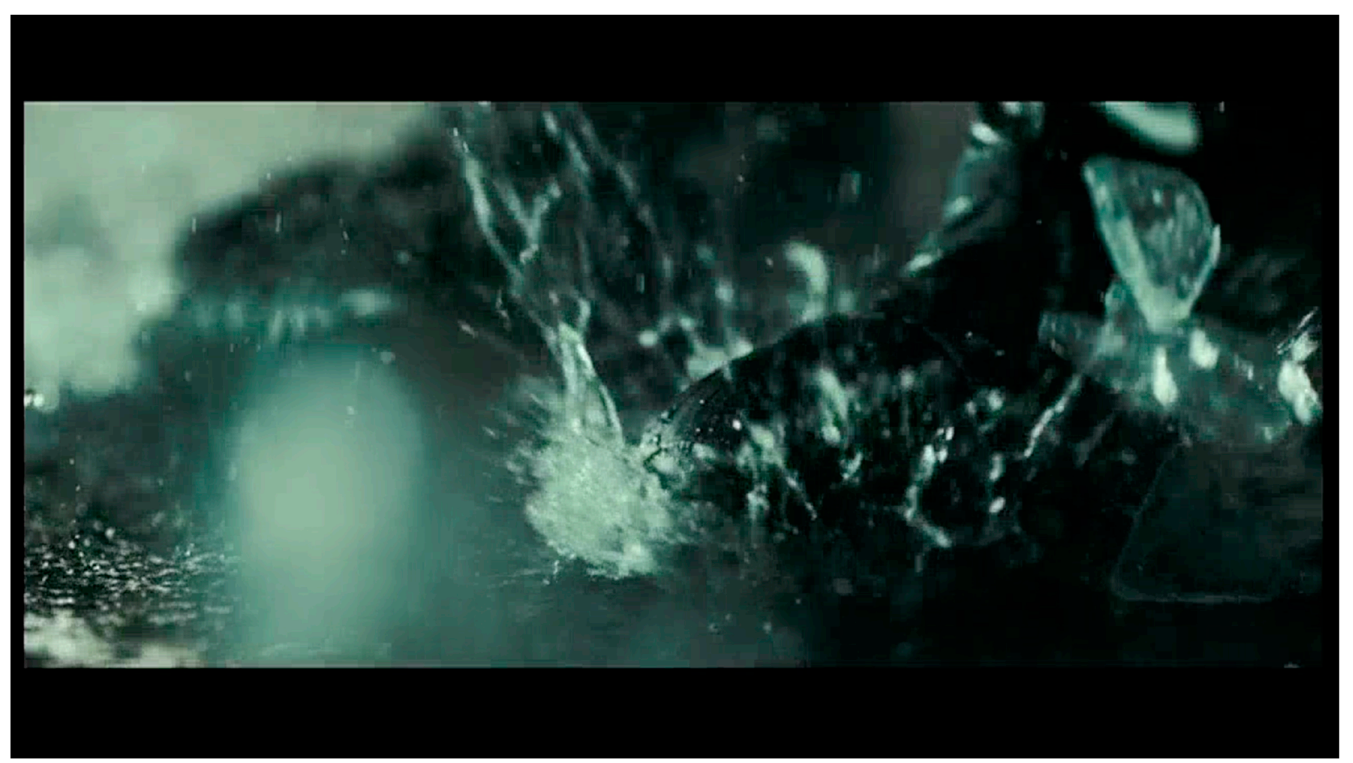

Figure 17. Lines of force ricochet across the frame in a kaleidoscopic spray. Frame capture, The Grandmaster (Wong 2013). 


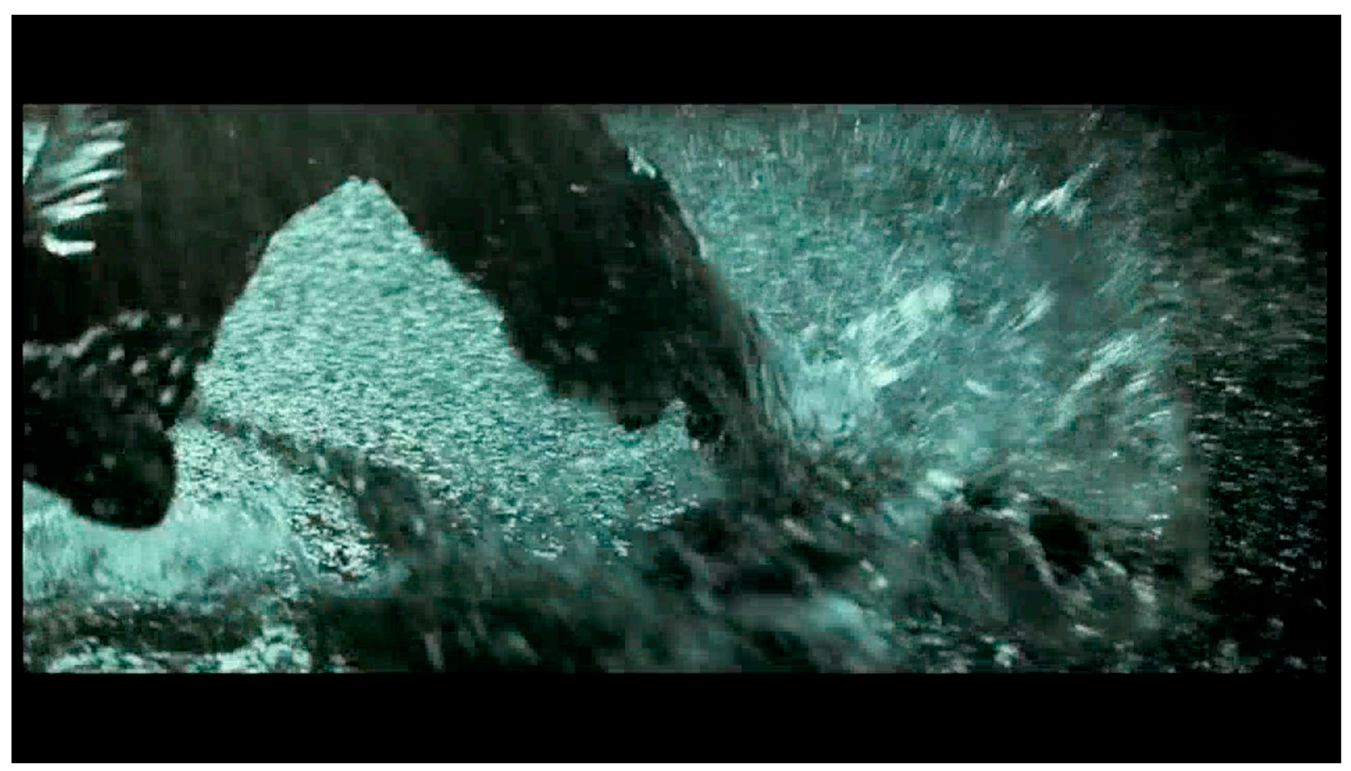

Figure 18. What moves across both figure and ground is power/energy/qi. Frame capture, The Grandmaster (Wong 2013).

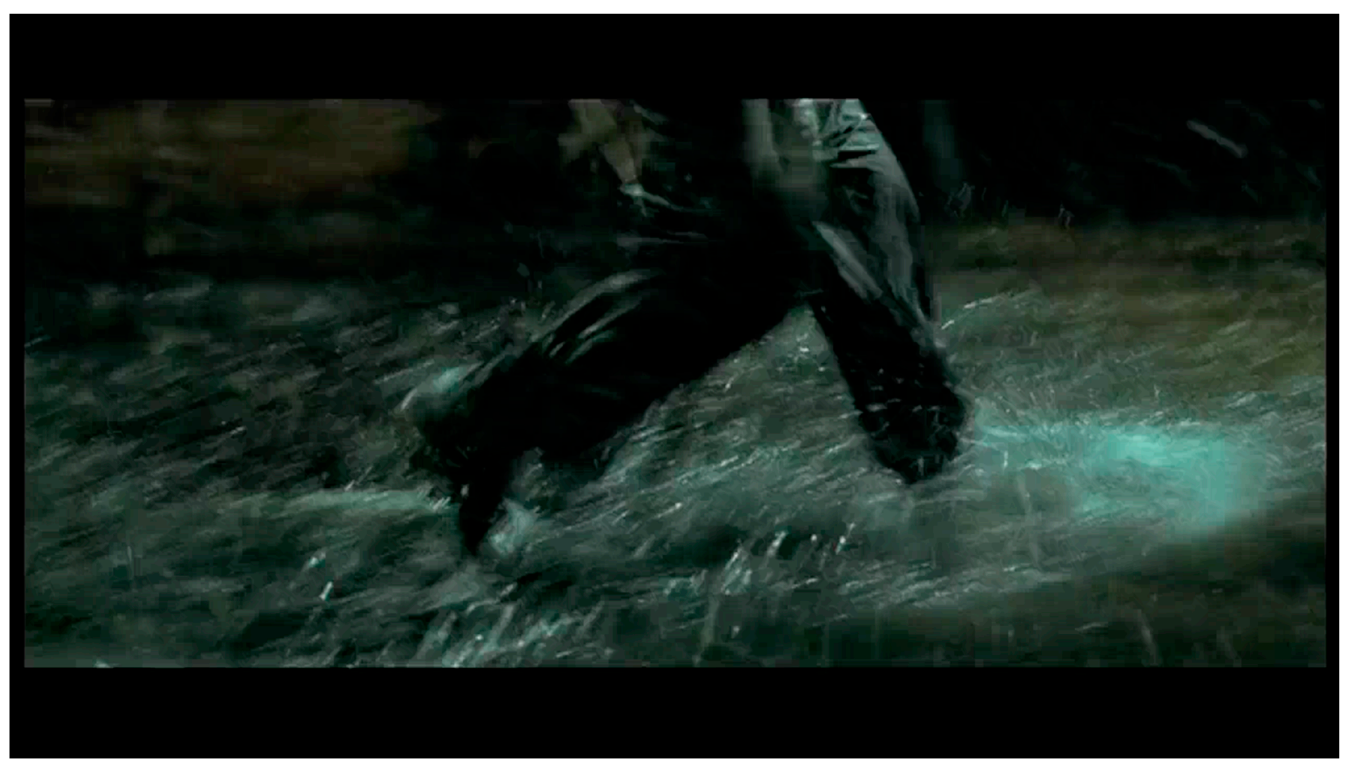

Figure 19. A seething tangle of movement that mimics an Abstract Expressionist painting. Frame capture, The Grandmaster (Wong 2013).

Many film critics have focused on the surface qualities of the action in Grandmaster-described as a 'ballet of the animate and inanimate colliding with incredible grace' (Sharkey 2014); 'by turns kinetic and balletic' (Dargis 2013); the 'use of shadows and silhouettes to convey movement' (Kennedy 2014) - and the techniques of cinematography and montage used to achieve it - the combination of lenses that 'transformed dark reflective rain puddles into black velvetine ink' (Compton 2013); 'impressionistic blurs and smears [ ... ] halted with a snap by a highly readable establishing shot and abrupt moments of stasis or hypersharp slowed motion' (Bordwell 2013). By contrast, the martial arts press emphasizes the culturally saturated tropes in the film, easily recognizable to anyone inculcated in the tradition of Chinese martial arts: 'purposefully hidden martial arts nuances', and the 'spirit of the Chinese dialogue, which eloquently masks the cryptic codes of martial skill and philosophy' (Reid 2015). Reviews and blogs dissect the action and, with a few 
small quibbles, attest to its authenticity, and cite the depth of research Wong conducted-three years interviewing hundreds of mainland martial artists (Chang 2013), the presence of martial artists on set who analyzed every move in the fight, and collaboration with screenwriter $\mathrm{Xu}$ Haofeng, who declares that 'only the barest essentials on screen evoke the physical philosophical and moral underpinnings of the martial arts disciplines' (Kraicer 2013).

Wong Kin-yuen claims that, in wuda pian, 'the cinematographic subject takes it upon itself to think with an embodied capacity, outside language, or with technesis as the narrating capability of the camera as a machine' (Wong 2005, p. 284). This idea can help us to understand the embodied philosophy of how 'subjects' can mobilize qi through the action of the trained human body. It also gives us an entrée into thinking about the cinematic rendering of this embodied thinking in physical, aesthetic form. At the crux of the intersection between the aesthetic and spiritual philosophy of Chinese martial arts and its cinematic rendering is revered martial arts choreographer, Yuen Woo-Ping, responsible for the fight scenes in both Crouching Tiger and The Grandmaster. Yuen trained from childhood in martial arts and Peking Opera combat (Chu 2012). He has been the most significant figure in martial arts choreography in Hong Kong cinema since his early work on Jackie Chan's Drunken Master (Woo 1978) and achieved international recognition with his work on The Matrix (Wachowski and Wachowski 1999).

\section{Figure/Ground}

Film philosopher William Brown cites The Matrix (Wachowski and Wachowski 1999) as a key turning point in the development of a new, non-anthropocentric cinema made possible by digital imaging technologies (Brown 2013). Brown is one among a swathe of film scholars who, influenced by Manovich, argue the centrality of digitalization to this "new" tendency (Manovich 2001). Indeed, the status of The Matrix (Wachowski and Wachowski 1999) stems from the integration of digital techniques and action into new composites, and Yuen acknowledges the importance of The Matrix (Wachowski and Wachowski 1999) in his work, saying that he learned, from the Wachowski brothers, how to 'combine computer graphics and martial arts choreography [ ... to] put a new spin on action' (Jackson 2016). Most of Grandmaster, however, was shot on celluloid. Wong says, in an interview with Martin Scorsese, 'I'm an analogue kind of guy', and cinematographer Le Sourd, while 'not absolutist about celluloid', reveled in working with the last Fuji film stock to shoot The Grandmaster (Deadline Hollywood 2014; Kennedy 2014).

Brown focuses on the relation between figure and ground to draw comparisons between analogue and digital cinema (Brown 2013, p. 53). He argues that 'animation has always been able to achieve those things that would be much harder to achieve in live action' and cites Manovich's claim that 'the digitization of film brings us back to animation' (Brown 2013, pp. 27, 275). Brown claims that, now, 'digital technology can enable films to depict [ ... ] space and all that fills it as a single continuum' (Brown 2013, p. 2). He cites Mark Hansen's work on 'technesis' to support his claim for an 'embodied complexity initiated by the advent of modern technologies' (Brown 2013, p. 274). In Brown's account, digital techniques enable 'a fundamental decentering of the figures', such that 'environments take on prominent roles', and on this basis he aligns digital cinema with an 'ecological logic' that 'suggests enworldment' (Brown 2013, pp. 2-3). According to Brown, in analogue cinema, 'typically [ ... ] figures stand in opposition to each other and the ground' and characters are '[individuals] in contrast to the space' (Brown 2013, p. 61).

One has to ask: which analogue cinema is Brown referring to? Orchestrating the relationship between figure and ground was certainly pivotal to the development of aesthetic strategies of cinema since its inception. Film scholars have described the 'polycentric image' of early cinema-an image which lacked depth and definition, in which figures and ground blended in an undifferentiated surface. The development of techniques to simulate depth in the image and to centre and focus on the figure-progressively refined through advances in lenses, depth of field, stocks and lighting setup-was an important step in the evolution of narrative cinema. And indeed, these evolving techniques embedded within them an assumed hierarchy: the primacy of the (usually) human figure 
that comes forward into dominance against a recessive background. However, an understanding of "ground" as inert, non-dynamic and recessive is in many cases more a problem of the inadequate theoretical frames used by film scholars to think cinema-most commonly in theatrical concepts of mise en scène as backdrop or profilmic that bear little relation to the dynamic, energetic operations of cinematic mise en scène, and the energetic work done by the integration of body and space in very many films. It cannot address the myriad ways that filmmakers have recalibrated this assumed hierarchy, exploring the potential to "give body" to the whole space of the frame: to make supposed "ground" perform as much as does "figure". To appreciate these trends, we need a performative understanding of mise en scène and of what the cinematic body means.

The capacity to deploy figure and ground on equal terms-to bring both figure and ground to life- - has been a staple of animation since the early Mickey Mouse cartoons, in which the drawn line of a "figure" would stretch, bend and snap back into place, and an environment would morph to match the body. This ability to render bodies plasmatic, and spaces and environments anthropomorphic, often served an Expressionist tendency to project the perceptual, cognitive and affective states of a character in graphic form into an environment. This represents one pole in a spectrum of approaches to reconfiguring the figure-ground relation: approaches that range from this Expressionist anthropomorphic doubling to, at the other pole, a play with figure-ground relations to decentre the body and dislodge anthropocentrism.

A few brief examples will here signal to these broader trends. In live-action cinema, within a shot captured by a still camera, moving objects and features of the natural environment such as grass or clouds can serve as haptic vectors of movement inside the frame, instigating a layer of kinetic rhythm in the shot, as in Satyajit Ray's exquisite cinematography of waterlilies rippling on the puckered, tactile shimmering surface of a wind-swept pond, in Pather Panchali, or Terrence Malick's framing of young girls in Days of Heaven behind a curtain of swaying wheat (Ray 1955; Malick 1978). These rhythms can create a multiplanar image in which "figure" and "ground" can move in complementary or disparate ways.

The mobile camera can multiply these kinetic rhythms into more flexible, dynamic and complex configurations, by counterposing movement and rhythm in the location and the movement of figures with movement of the frame itself. In Voyage to Italy for example, as the camera tracks along a Naples Street, women push prams in one direction, forward to left of frame, and pillars in the location appear to glide backwards across the frame in the opposite direction, pulling the viewer's attention, splitting it between supposed "foreground" and "background" - an oscillation that dramatically increases the dynamic energy of the shot, dispersing the viewer's attention and making the "ground" perform as a "figure" as much as the humans / characters do (Rossellini 1954). The shot translates emotional confusion into spatial dislocation, and the viewer is drawn in physically to experience the climactic disorientation and desperation of the character through the perceptual fracturing produced by conflicting rhythms and directions. The aesthetic strategy of dispersing energy and focus equally between figure and ground reinvents the polycentric image as a site of complex, dispersed intensities.

In A Woman Under the Influence, John Cassavetes explores the potential of these complex graphic and energetic resonances and conflicts to undermine a character's subjectivity rather than to mirror it (Cassavetes 1974). The handheld camera tracks restlessly, following Gena Rowlands as she prances back and forward along a busy street. Echoing Rossellini's play with the vertical axis of pillars and the horizontal axis of the tracking camera, multiple telegraph poles gliding by emphasize the vertical, accentuating Rowlands' long bare legs in short schoolgirl skirt, while the centrality of her moving body is constantly undercut by the horizontal chaos of traffic whizzing by on the busy street. The multiple points of focus and conflicting rhythms of the polycentric image decentre Rowlands, an affective fracturing that renders her at the mercy of the multiple forces swirling around her: fragmented, ontologically less stable, less grounded, fragile like flotsam pulled around by the city tide.

In 400 Blows, Truffaut radically exceeds the subjective deployment of "ground", when he films a young boy suspended and spun in a carnival rotor (Truffaut 1959). The scene cuts back and forward 
between the body of the boy clearly demarcated against the boards of the rotor, a long shot of the spinning rotor that confounds depth and perspective, rendering it as a two-dimensional spinning surface, and the boy's point of view from the centrifuge of the rotor to the people watching above, who lose all coordinates as they and the space they occupy appear to spin ever faster around the top of the rotor. Rather than simply projecting emotional or perceptual states onto the environment, the scene plays with depth and surface, movement and stasis in a way that surrenders the viewer's kinaesthetic cues to the sheer pleasure of a decentred kinetic delirium.

The Pride of Strathmoor (Baldvin 2014) and The Grandmaster (Wong 2013) serve as potent exemplars to contest claims that digital cinema is inventing 'new' relationships between human and environment that were not possible in analogue cinema. The list could go on, through the cinema of Wong, Tarkovsky or Tarr, of Cassavetes, Rossellini, Ray, Malick, Mizoguchi, Truffaut or Denis, and many others. All of these cineastes working in analogue cinema, to varying degrees, envision a cinema in which figure and ground are understood on equal terms. All work with an understanding of mise-en scène as dynamic, material and embodied. All move in and out of scenes in which spatial composition, mobile camera, cinematography and/or cutting work to maximize the dynamic integration of space and body, figure and ground.

Inheriting these many experiments in figure-ground relations, the achievement of the fight scene in the rain in Grandmaster demonstrates that, in live-action cinema, the digital/analogue divide does not necessarily mark a decisive rupture that makes possible a new non-anthropocentrism. It is the aesthetic, cinematic and philosophical principles that underpin a film that determine the approach it takes to the relationships between humans and their environment. Rather than a rupture enabled by technology, this stems from a specific concept of what cinema is and can be-an understanding of the cinematic that finds new means for its realization in the capacities of digital imaging techniques.

\section{To Engage with the Cinematic Body}

Highlighting the embodied capacity in performance that characterizes wuda pian, Wong Kin-yuen's analysis crystallizes the need to think about how we as viewers engage with this embodied mode (Wong 2005). What does it mean to 'get' something cinematically, materially, through this dispersed, embodied mode of viewing? To engage with the cinematic body, understood in this fully cinematic way? Many filmmakers and theorists have attempted to grasp this embodied engagement, from Eisenstein's proposal of a mode of sensuous or 'pre-logical' thought, through Bálàsz and his influence on Benjamin and Kracauer's explorations of the modes of sensuous, tactile perception that Benjamin refers to as the mimetic faculty, into more recent phenomenological approaches to thinking and writing about embodied spectatorship and affect, performance and the cinematic body, and emerging studies of embodied cognition informed by recent developments in neuroscience. This is the question that goes to the heart of this mysterious medium in all its technological manifestations, animation, live action and digital. The answer remains just as elusive now as ever.

Conflicts of Interest: The author declares no conflict of interest. This research was not funded.

\section{References}

Baldvin, Einar, dir. 2014. The Pride of Strathmoor. USA: USC Student Film.

Bordwell, David. 2013. The Grandmaster: Moving Forward, Turning Back. David Bordwell's Website on Cinema. Available online: http:/ / www.davidbordwell.net/blog/2013/09/23/the-grandmaster-moving-forwardturning-back/ (accessed on 1 November 2016).

Brown, William. 2013. Supercinema: Film-Philosophy for the Digital Age. New York: Berghahn Books.

Cassavetes, John, dir. 1974. A Woman under the Influence. USA: Faces.

Chang, Justin. 2013. In 'The Grandmaster,' Wong Kar Wai Takes Audiences on an Ip Trip. Variety. Available online: http:/ / variety.com/2013/biz/news/in-the-grandmaster-wong-kar-wai-takes-audienceson-an-ip-trip-1200575645/ (accessed on 1 November 2016). 
Chu, Karen. 2012. Matrix' Fight Choreographer Talks Working with Keanu Reeves, Jackie Chan. Hollywood Reporter. Available online: http:/ / www.hollywoodreporter.com/news/yuen-woo-ping-matrix-keanu-reeves-jackiechan-343220 (accessed on 1 November 2016).

Compton, James. 2013. The Grandmaster-Wong Kar Wai. Cinematography Forums. Available online: http: / / www.cinematography.com/index.php?showtopic=61004 (accessed on 1 November 2016).

Dargis, Manohla. 2013. Style and Kinetics Triumph in a Turbulent China. The New York Times. Available online: http:/ / www.nytimes.com/2013/08/23/movies/the-grandmaster-wong-kar-wais-newfilm.html (accessed on 1 November 2016).

Deadline Hollywood. 2014. Martin Scorsese and Kar Wai Wong Interview. Available online: http://deadline. com/2014/01/oscars-martin-scorsese-interviews-grandmasters-wong-kar-wai-video-66155/ (accessed on 1 November 2016).

Ebiri, Bilge. 2013. Director Wong Kar-Wai Explains Three Key Scenes from The Grandmaster. Vulture. Available online: http://www.vulture.com/2013/08/wong-kar-wai-explains-three-scenes-from-thegrandmaster.html (accessed on 1 November 2016).

Jackson, Andy. 2016. An Interview with Yuen Woo Ping. Retro Domination. Available online: http://www. retrodomination.com/an-interview-with-yuen-woo-ping/ (accessed on 1 November 2016).

Kennedy, Gerard. 2014. Philippe Le Sourd on Shooting 'The Grandmaster' and the Historic Final Roll of Fujifilm. Hitfix. Available online: http:/ / uproxx.com/hitfix/phillipe-le-sourd-on-shooting-the-grandmaster-andthe-historical-final-roll-of-fujifilm/ (accessed on 1 November 2016).

Kraicer, Shelly. 2013. One Horizontal, One Vertical: Some Preliminary Observations on Wong Kar-Wai's The Grandmaster. Cinema Scope 54. Available online: http://cinema-scope.com/features/onehorizontal-one-vertical-some-preliminary-observations-on-wong-kar-wais-the-grandmaster/ (accessed on 1 November 2016).

Laughton, Charles. 1955. The Night of the Hunter. USA: Paul Gregory Productions.

Lee, Ang. 2000. Crouching Tiger, Hidden Dragon. Taiwan: Asia Union Film \& Entertainment Ltd.

Leyda, Jay and Naum Kleinman, eds. 1988. Eisenstein on Disney. London: Methuen.

Malick, Terrence, dir. 1978. Days of Heaven. USA: Paramount Pictures.

Manovich, Lev. 2001. The Language of New Media. Cambridge: MIT Press.

Marks, Laura U. 1999. The Skin of the Film: Intercultural Cinema, Embodiment, and the Senses. Durham: Duke University Press.

Ray, Satyajit, dir. 1955. Pather Panchali. India: Government of West Bengal.

Reid, Daniel. 1998. A Complete Guide to Chi-Kung: Harnessing the Power of the Universe. Boston: Shambhala.

Reid, Carig D. 2015. The Grandmaster: Why You Should See This Ip Man Biopic. Black Belt Magazine. Available online: http: / /www.blackbeltmag.com/daily/martial-arts-entertainment/martial-art-movies / the-grandmaster-why-you-should-see-this-ip-man-biopic/ (accessed on 1 November 2016).

Rizov, Vadim. 2014. The Grandmaster Review. Sight E Sound, no. 1. Available online: http:/ /www.bfi.org.uk/ news-opinion/sight-sound-magazine/reviews-recommendations/film-week-grandmaster (accessed on 1 November 2016).

Rossellini, Roberto, dir. 1954. Voyage to Italy. Italy: Italia Film.

Rutherford, Anne. 2011. 'What Makes a Film Tick?': Cinematic Affect, Materiality and Mimetic Innervation. Bern: Peter Lang.

Scorsese, Martin. 1980. Raging Bull. USA: Chartoff-Winkler Productions.

Sejean, Nathalie. 2013. Working with Wong Kar Wai: Dop Philippe Le Sourd Describes the Experience of Shooting The Grandmaster. Mentorless. Available online: http:/ /www.mentorless.com/2013/08/23/working-withwong-kar-wai-dop-philippe-le-sourd-describes-the-experience-of-shooting-the-grandmaster/ (accessed on 1 November 2016).

Sharkey, Betsy. 2014. Subtle Shades of Greatness Frame Cinematography Nominations. Los Angeles Times, January 17. Available online: http:/ / articles.latimes.com/2014/jan/17/entertainment/la-et-mn-oscar-2014nominations-cinematography-betsy-20140117 (accessed on 1 November 2016).

Stasukevich, Iain. 2014. Audio podcast, talk with cinematographer Philippe Le Sourd, the American Society of Cinematographers. The Grandmaster. Available online: https:/ /itunes.apple.com/no/podcast/americancinematographer-podcasts/id259748235?mt=2 (accessed on 1 November 2016). 
Stern, Lesley, and George Kouvaros. 1999. Descriptive Acts. In Falling for You: Essays on Cinema and Performance.

Edited by Lesley Stern and George Kouvaros. Sydney: Power Publications, pp. 1-35.

Truffaut, François. 1959. 400 Blows. France: Les Films du Carrosse.

Wachowski, Lana, and Lilly Wachowski. 1999. The Matrix. USA: Warner Bros.

Wiene, Robert. 1920. The Cabinet of Dr Caligari. Germany: Decla-Bioscop AG.

Wong, Kin-yuen. 2005. Technoscience Culture, Embodiment and Wuda Pian. In Hong Kong Connections: Transnational Imagination in Action Cinema. Edited by Siu Leung Li, Meaghan Morris and Stephen Chan Ching-kiu. Durham: Duke University Press; Hong Kong: Hong Kong University Press.

Wong, Kar-wai. 2013. The Grandmaster. Hong Kong: Block 2 Pictures.

Woo, Ping-Yuen. 1978. Drunken Master. Hong Kong: Seasonal Film Corporation.

(C) 2017 by the author. Licensee MDPI, Basel, Switzerland. This article is an open access article distributed under the terms and conditions of the Creative Commons Attribution (CC BY) license (http://creativecommons.org/licenses/by/4.0/). 